\title{
A comparative study of collaborative learning in Paper Scribbles and Group Scribbles
}

\author{
Chen Fang Hao \\ Nanyang Technological University
}

\begin{abstract}
Paper Scribbles (PS) consisting of markers, vanguard sheets and 3M Post-It notes, is a pedagogical tool to harness collective intelligence of groups for collaborative learning in the classroom. Borrowing the key features of PS and yet avoiding some of their physical limitations, a computer-based tool called Group Scribbles (GS) was designed to enable high performance synchronous, face to face collaborative experiences in the classroom. In our exploratory study, we discuss and compare the different properties of PS and GS technologies in two elementary grade 5 classes. The findings reveal that there are not only physical and technical differences but more importantly, pedagogical differences between the two technologies that accounts for different collaborative learning mechanisms.
\end{abstract}

\section{Introduction}

Traditional patterns of classroom talk have evolved over a significant period of time, and are continuously reproduced as part of institutionalised schooling. Analysis of classroom discourse has been the subject of extensive educational research (e.g. Cazden, 1988; Edwards \& Westgate, 1994; Mercer, 1995). The most typical or default pattern of classroom interaction is the initiation-response-evaluation (IRE) pattern which has been shown to account for a possible $70 \%$ of teacher-student classroom interactions (Nassaji \& Wells, 2000). In the IRE, a teacher initiation (I) is followed by a student reply $(\mathrm{R})$, followed by an evaluation of this reply (E) by the teacher. In this pattern, the teacher initiates discussion, usually with a question, students respond and the teacher provides feedback in the form of evaluation. IRE has been criticised for leading to unrewarding and boring classroom discussions. Changing such deep seated, traditional patterns of classroom discourse poses a considerable degree of challenge for classroom reform.

Moreover, there is an ever-increasing need to provide students with learning experiences that reflect the challenges and opportunities they will experience in the workforce of the 21st century. One key class of workforce skills relates to rapid collaborative knowledge building (RCKB). RCKB techniques include problem identification, brainstorming, prioritising, concept mapping, and action planning (DiGiano, Tatar \& Kireyev, 2006). By harnessing these techniques in the classroom, it is possible for students both to learn existing subject matter more deeply and also to become participants in 21st century knowledge building practices. These techniques can be enacted with lightweight technology such as sticky paper notes (also known as Paper Scribbles (PS) or Post-It notes or "scribble sheets"), or digital technologies such as student response systems (also known as audience response systems, electronic voting 
systems, and other names). In PS, easy-to-use sticky notes were adopted to facilitate the students' use in contributing ideas to an activity posed by the teacher. For example, they may use sticky notes to guess animals based on the characteristics given by each other, post the name of the organs in the human digestive system, post different living organisms in a particular habitat, and classify fruits according to different characteristics, etc. In addition, students may use sticky notes to comment on each others' postings (Ng, Looi \& Chen, 2008; Tan, Chen \& Looi, 2009; Looi, Chen \& Ng, 2010). An example of PS is shown in Figure 1 below. A more sophisticated solution is Group Scribbles (GS), developed by SRI international, which enables collaborative generation, collection and aggregation of ideas through a shared virtual space based upon individual effort and social sharing of notes in graphical and textual form.

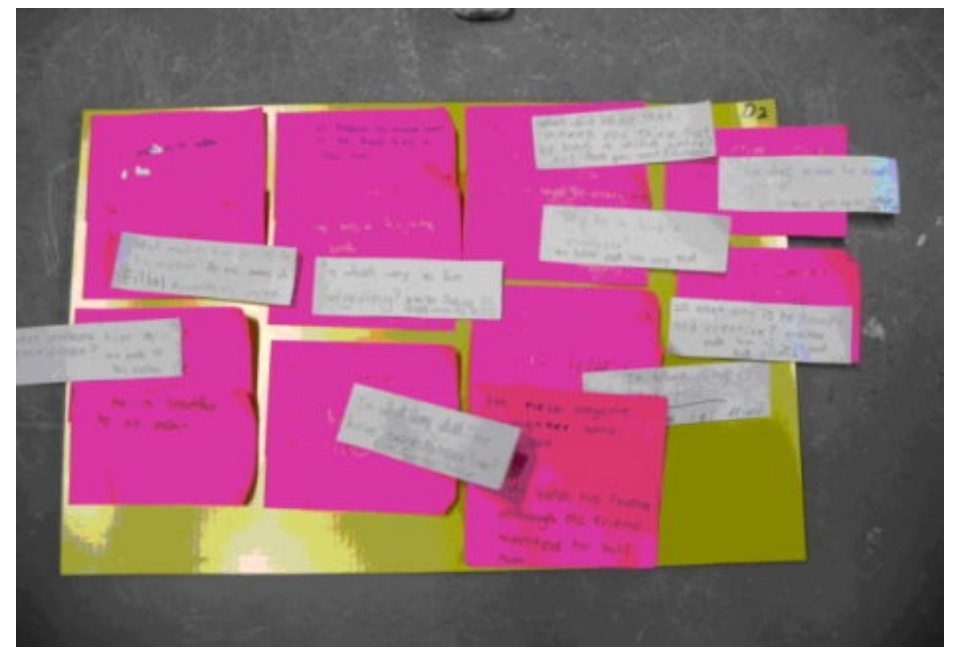

Figure 1: Posting and peer commenting of ideas in Paper Scribbles (PS)

\section{Group Scribbles as a technology for RCKB}

The GS user interface presents each user with a two-paned window. The lower pane is the user's personal work area, or "private board", with a virtual pad of fresh "scribble sheets" on which the user can draw or type (Figure 2). The essential feature of the GS client is the combination of the private board where students can work individually, and group boards or public boards where students can post their work by positioning it relative to others', view others' work, and take items back to the private board for further elaboration. Students can view and comment other group boards using a "swap board" feature. Figure 2 shows a lesson activity in class in which each student posts answers to the question "When does the heart beat faster/slower?" in the private board, and then move their answers to the public board for sharing. The students' scribble notes showed a multiplicity of ideas they generated which enabled the teacher to initiate discussions on the interesting postings. For example, one student posted "just before examination" in the state of "faster heartbeat", a contribution which surprised the teacher and the class, and which prompted the teacher to initiate a discussion on why this might be the case.

In collaborative classrooms, groups of learners and their teachers routinely work in more complex configurations than lecture based classes. They take roles, contribute 
ideas, critique each other's work, and together solve aspects of larger problems, all to good effect (Hake, 1998). Managed flow of information and control is essential to the structure of many of these successful educational activities (Guribye, Andreassen \& Wasson, 2003).

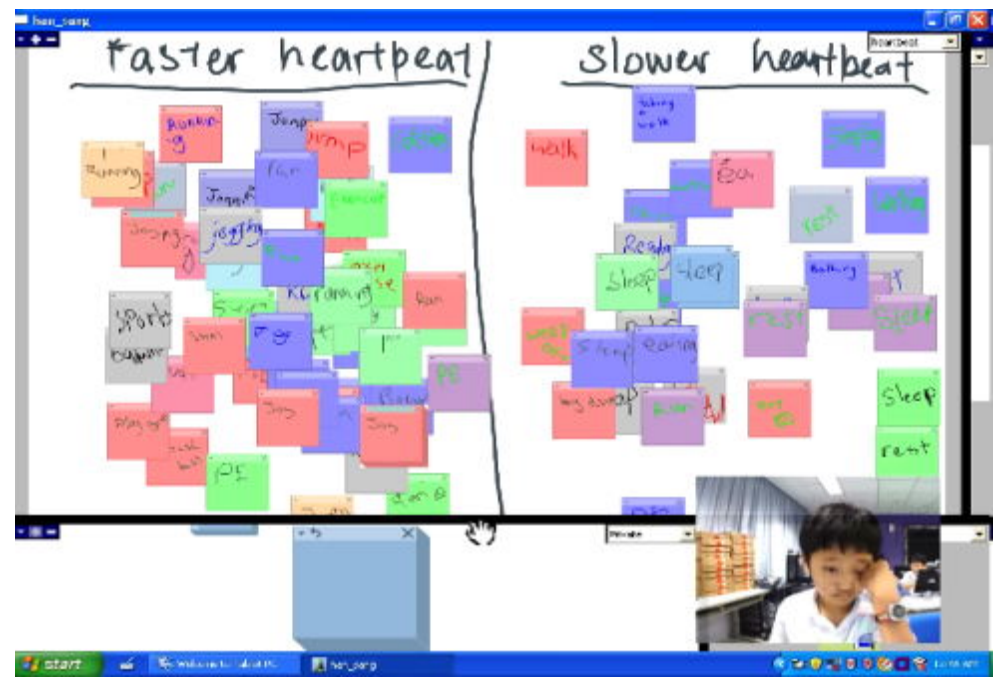

Figure 2: A Morae screenshot of the public or group board (upper pane) and private board (lower pane)

However, there remains a common question by users of both technologies: Besides differences in physical and technological characteristics, do they essentially cater to the same pedagogy and produce the same collaborative learning patterns for students? In our exploratory study, we investigate the physical, technological and pedagogical similarities and differences between both technologies in a systematic way. At the end of our study, we make preliminary comparisons between the two technologies.

\section{Research context}

\section{Research and intervention context}

In Singapore, the school year starts in January and ends in November. We started our study in July 2007 working with two teachers in a primary (elementary) school in Singapore. Both teachers teach different classes in elementary grade 4 where students' median age is about 10 years old. One class consists of high ability students while the other consists of average ability students. We started with 6 weeks of Paper Scribbles (PS), which are activities using sticky paper notes, in the classrooms as an initiation phase. This was intentional as a means to begin enculturating the teachers and the students into the practice of rapid collaborative brain-storming and critiquing, and to the relevant protocols and social etiquettes. In the initiation activities, students worked in group of four. They first posted sticky notes on an A4 size magnetic boards ("group boards") and then put them on the class whiteboard for other groups to see. Sometimes teachers put the group boards under the visualiser in order to let all students see the board at the same time. The groups were pre-formed by the teachers. This worked well as members in groups interacted with one another face to face. 
Subsequently, the class switched to the use of the GS technology for 10 weeks. The students and teachers were provided training for two sessions of an hour each. They then used GS for science lessons for another 10 weeks. Each week they had one hour GS Science lesson in the computer laboratory. The GS network in our study utilises wired local area network (LAN) configuration. In our instructional design, we tried to incorporate the following 10 principles, of which the latter five were adapted from Scardamalia (2002):

- distributed cognition - designing for thinking to be distributed across people, tools and artefacts,

- volunteerism - letting learners choose what piece of the activity they want to participate in,

- spontaneous participation - designing for quick, lightweight interaction driven by students themselves,

- multimodal expression - accommodating different modes of expression for different students,

- higher order thinking - encouraging analysis, synthesis, evaluation, sorting, categorising, etc,

- improvable ideas - providing a conducive environment where ideas can be critiqued and made better,

- idea diversity - exploring ideas and related/contrasting ideas, encouraging different ideas,

- epistemic agency - encouraging students to take responsibility for their own and one another's learning,

- democratised knowledge - everybody participates and is a legitimate contributor to knowledge,

- symmetric knowledge advancement - expertise is distributed, and advanced via mutual exchanges.

From Jan to Oct 2008, we continue our involvement with the teachers; the students are now in elementary grade 5 (students' median age is about 11 years old). Every week for 10 weeks, two lesson periods (totaling an hour and 10 mins) for the subjects of science (for 2 semesters) and mathematics (for 1 semester) adopted GS lessons which were conducted in a computer lab. In this class of 40 students, each pupil has an individual Tablet-PC (TPC) with a GS client software installed.

\section{Technology comparison experimental design}

In our study, we wanted to investigate the physical, technological and pedagogical similarities and differences between both technologies in a systematic way. Hence, we designed two quasi-experiments for two science lessons in both classes. In these lessons, the topics taught in both classes were of a similar nature, i.e. forces and levers. For each lesson, the class was divided equally into two sections. One section used PS technology while the other used GS technology for their group work activity. Hence, teachers had to design similar group activities within the same lesson that could be undertaken by both technologies e.g. physical Gallery Walk (PS) vs. virtual Gallery Walk (GS), posting of individuals' ideas using Post-It notes (PS) vs. electronic scribbles pads (GS), peer commenting using smaller Post-It notes (PS) vs. electronic label pads (GS), etc. Gallery Walk describes a particular group activity where students exhibit and/or explain their group board to one another in a systematic way. Within a certain time limit, groups will view, comment, and from learn from other groups' boards on a rotational basis. In PS, this involved physical movement of students and/or PS boards 
while in GS, viewing and commenting upon other groups' boards are done via the "swap board" feature of the software. It is worthwhile to note here that, in groups that used PS technology, there were no TPCs present on the group table as shown in Figure 3. In the following week, there was a swap of technologies between the two sections. In this way, we could observe the behaviour of each student using each technology. In this design, the confounding effects arising from different teachers, topics, classroom environment and students' emotional states were minimised to ensure quality comparison between PS and GS technologies.

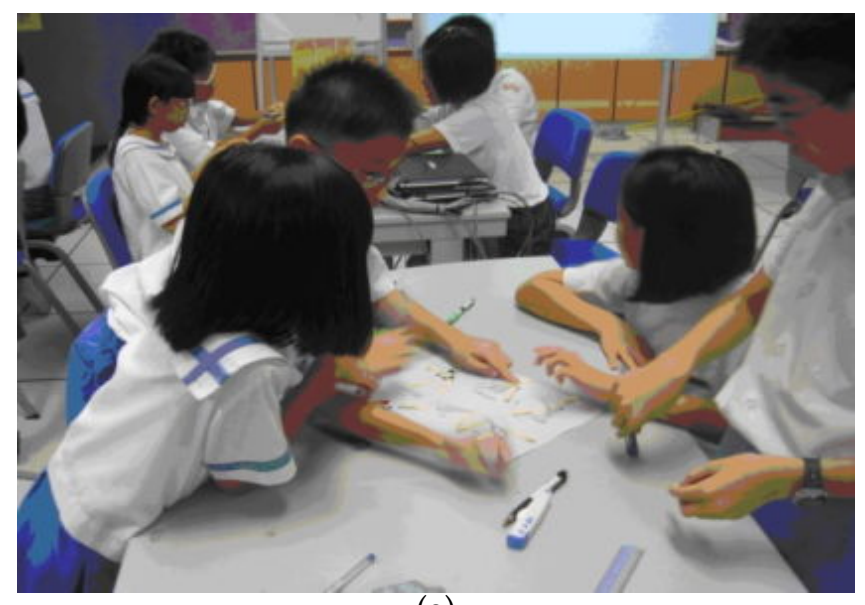

(a)

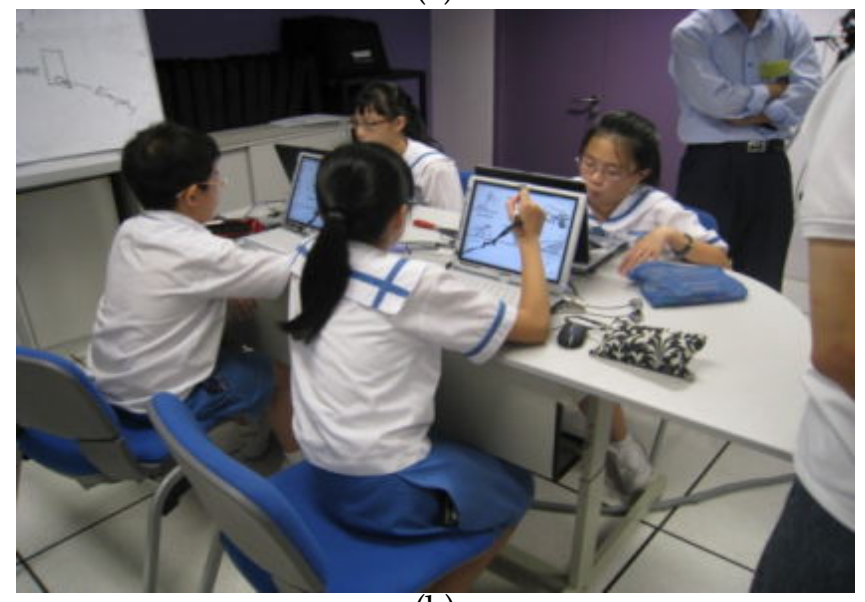

(b)

Figure 3: Students in groups of four using (a) PS technology and

(b) GS technology within the same class lesson.

\section{Data collection and analysis}

In our collection of data, two or more researchers observed each class and took down detailed field observation notes. One video camera was set at the back of the classroom to record the classroom session, while two other video cameras were focused on two target groups of students. Screen capturing software Morae 2.0 was installed on the TPCs to record the interaction of the pupils using GS. We tried to analyse these videos 
from different perspectives including uptake analysis (Looi, Chen, Tan, Wen \& Wee, 2008), as well as analyse data from surveys, interviews and performance tests (Chen \& Looi, 2008). We have also employed semi-structured interviews with the teachers and selected students as the method to gain access to the subjective understanding of the teacher. This included an hour long interview conducted at the end of the semester and weekly post lesson conference sessions.

In post lesson conference sessions, the researchers and the teacher discussed the lesson that had been implemented. The researchers prompted the teacher to reflect on the lesson that had transpired and articulate in the verbal discussion. The immediacy of the conference session after the lesson ensured that the teachers did not forget the teaching episodes that they have taught, and thus were able to provide better feedback and discussion. At the end of semester interview session, the teacher was interviewed by two researchers with a list of prepared interview questions in a private location. The interview sessions were audio and video recorded. After the interview session, the interview session was transcribed to create written protocols for analysis.

This study employs a qualitative cross case comparison method for data analysis in three areas: physical, technological and pedagogical. In each area, we focused on students' interactions within and between groups and how each technology was leveraged in each interaction category. Multiple data resources were used and analysed in each area. Data from video, surveys and interviews were analysed and triangulated to understand any interesting phenomenon.

\section{Results and discussion}

This section discusses some of the salient physical, technological and pedagogical similarities and differences between PS and GS that we have observed and analysed from our study. It is worthwhile to note here that some of the pedagogical similarities and differences result from the inherent physical and technological similarities and differences between the two technologies. Hence, the interplay of the physical and technological properties of each technology produces different pedagogical effects.

\section{Physical and technological differences}

Essentially, PS consumes much more physical resources compared to GS. In every PS lessons that we have conducted, much logistical preparation is needed. Mahjong papers, vanguard sheets, Post-It sticky pads of various sizes and colors, markers, etc, have to be prepared before each lesson. In order to not distract the students, materials for PS were distributed only during the relevant group activities in each lesson. This generated a lot of manual busy work, i.e. handing out materials in an orderly fashion, collecting, moving from place to place, etc, for teachers and student alike, and precious lesson time was lost during this process. We have recorded an approximate timing of 3 to 5 minutes for such manual work to be completed in each PS activity. In addition, there were constraints placed by the school, a limiting of the supply of PS materials. Teachers and students had a limited supply of Post-it sticky pads for posting their ideas and commenting on the ideas of others. In conjunction with the school's "Clean and Green" initiative (an initiative to educate students about environmental conservation), students were told not to "waste" these sticky pads and were encouraged to write as much content as possible on one sticky pad. Below is an excerpt from a teacher-student conversation during class: 
Student A: Teacher, how much can we write on one sticky pad?

Teacher: $\quad$ Write as much as possible. I have limited supply of sticky pads in class. Also, remember our "Clean and Green" initiative? We must do our part in saving the earth and try not to waste any sticky pads.

In comparison, students take a lesser time of about 1 to 2 minutes to log into the GS user panel. There were little movement in this section of the class and thus, classroom management by teacher was reduced. In addition, GS utilises unlimited virtual resources for students to post and comment. There were no concerns with environment conservation and students can freely post as many ideas as possible. More often than not, we see students posting one idea per scribbles pad in GS as shown in Figure 4.

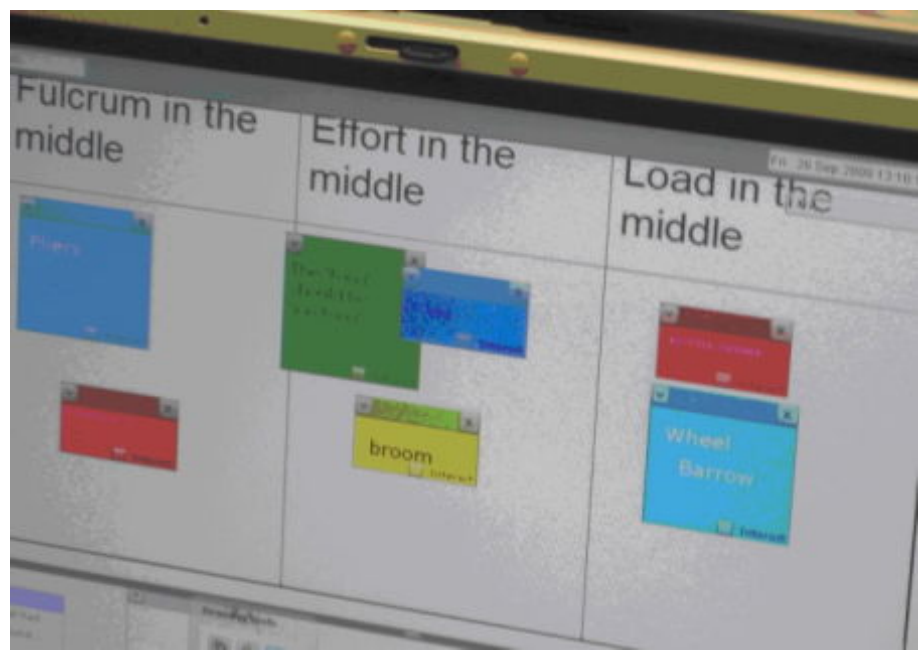

Figure 4: One idea per GS scribble pad

Another physical limitation of PS is, sticky pads do not stick for long. After some time, sticky pads may drop off from their original positions. This is an irritation to both the teachers and students as they spend time and effort guessing the original positions of the sticky pads and sticking them back. In our study, we found that this happened quite frequently, despite the fact that reasonably good quality sticky pads were used. However, this limitation is overcome by GS technology. Virtual learning artefacts in GS generally remain persistent and permanent. Teachers can digitally store these artefacts and reproduce them individually (either digitally or hardcopy printouts) among the students either for after class purposes, for example continuing any unfinished work after class; individual students can revisit of any learning artefacts done either own group or other groups; or for the purpose of continuing from where students left off at the end of the previous lesson.

However, work done by PS cannot be reproduced individually for all students. Much effort would have to be put in to photocopy every learning artefact for the whole class. These laborious efforts usually deter most teachers. In our study, usually teachers moved every group board to a particular classroom for common viewing. Lastly, GS enables a teacher to project any group board conveniently on an interactive white board (IWB) for class teaching and for students' presentations (Figure 5). This feature is also very useful for any group presentation to be done. In comparison, we found 
that projection of a particular PS board from the visualiser often cannot encompass the whole group board. Moreover, movement of the PS board beneath the visualiser often causes some Post-It sticky pads to drop off. This causes unnecessary hassle both for the teachers and students.

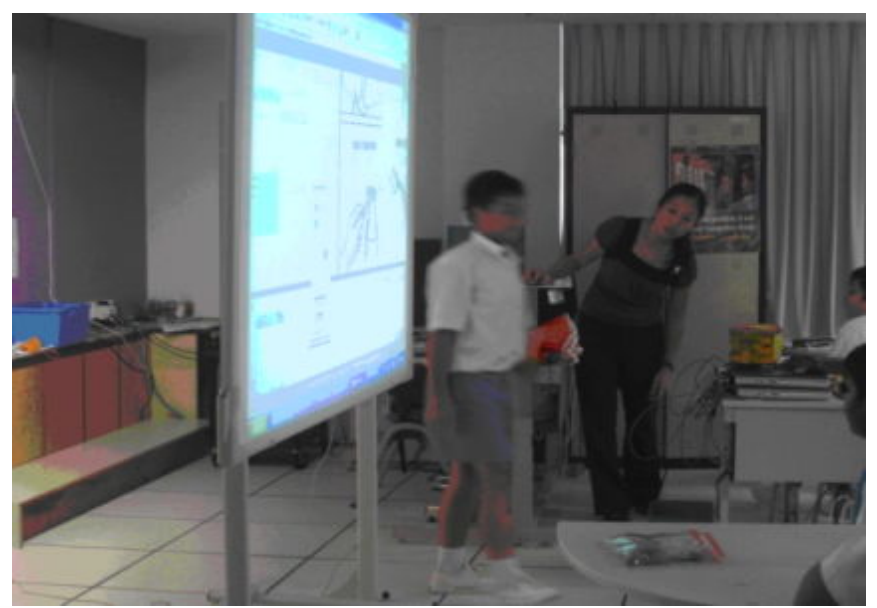

Figure 5: Student using the IWB to project his group board for oral presentation during a GS lesson

However, implementing GS technology in schools does impose certain limitations and trade-offs. In the setup of GS technology, the school needs to invest money, effort and time to purchase computer hardware and software to setup the network. As with most ICTs, there exists a risk of occasional technical glitches during lessons. In our research work, technical glitches ranging from minor to major problems occurred from time to time during our lesson observations and data collection. Therefore, it is necessary to provide students, teachers and school technical assistants with the necessary support, especially during the initial phase. This is described in detail in another paper (Chen \& Looi, 2009). With PS technology, these issues are of no concern.

Despite the numerous physical and technological differences, PS and GS provide a common platform for individual students to post their ideas. This platform enable publication of students' ideas to other people, i.e. classmates, teachers, etc, for viewing, peer commenting, ideas organising and presentation purposes.

\section{Pedagogical differences and similarities}

One of the common group work pedagogies is Gallery Walk. This allows students to view other group boards and hence, enables them to learn from one another by commenting, questioning and viewing each other's ideas. This can be done with or without stationing a presenter at the respective group boards. PS and GS technologies provide different ways for conducting Gallery Walk in class that result in different pedagogical effects. In PS, it is difficult for everyone in the class to view a sticky note immediately, simultaneously, and remotely when someone publishes it. This is evident when students need to view group boards from other groups. Students are required to get up from their seats and move around physically in the class (Figure 6) to do Gallery Walk. Although this may benefit kinesthetic learners, it poses additional classroom management issues for the teacher. In our research study, we observed that, 
in the midst of all the physical movements, students abused this opportunity, by engaging in casual chit chatting and misbehaviour that disrupted learning in the class.

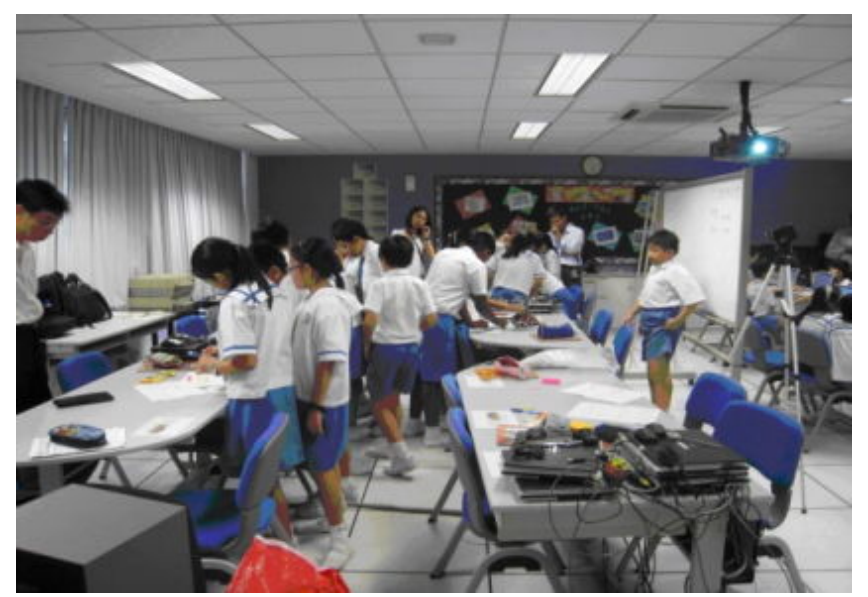

Figure 6: Physical movements in PS group

Hence, strict time and behavioural management must be imposed on the class, in order for students to benefit from this activity. Some teachers attempt to reduce such misbehaviour in class by implementing systematic exchange of group boards. In other words, either the PS group boards are interchanged among adjacent groups without any physical walking, or the appointed group leader of each group is allowed to swap the group boards. Although this decreases the occurrences of misbehaviour, volunteerism and epistemic agency are compromised as each student is constrained to peer comment on a certain group board at a time. This may result in a reduction of ideas contribution and diversity, especially if "groupthink" is prevalent in a group. Hence, there are two ways that Gallery Walk can be conducted in PS, as shown in Table 1, each with different advantages and disadvantages.

Table 1: Types of gallery walk in PS

\begin{tabular}{|c|l|l|l|l|}
\hline \multicolumn{2}{|c|}{ Types of gallery walk } & \multicolumn{1}{|c|}{ Description } & \multicolumn{1}{c|}{ Advantages } & \multicolumn{1}{c|}{ Disadvantages } \\
\hline 1. & $\begin{array}{l}\text { Free random } \\
\text { movement of } \\
\text { any student. }\end{array}$ & $\begin{array}{l}\text { Every student is given free } \\
\text { choice to choose any group } \\
\text { boards to go to. }\end{array}$ & $\begin{array}{l}\text { Epistemic agency, } \\
\text { volunteerism and } \\
\text { idea diversity is } \\
\text { preserved. }\end{array}$ & $\begin{array}{l}\text { In our research } \\
\text { study, this has the } \\
\text { highest occurrences } \\
\text { of misbehaviour. }\end{array}$ \\
\hline 2. & $\begin{array}{l}\text { Systematic } \\
\text { swapping of } \\
\text { group boards. }\end{array}$ & $\begin{array}{l}\text { The PS group boards are } \\
\text { interchanged among } \\
\text { adjacent groups without } \\
\text { any physical walking or the } \\
\text { appointed group leader of } \\
\text { each group is allowed to } \\
\text { swap the group board. }\end{array}$ & $\begin{array}{l}\text { Epistemic agency, } \\
\text { volunteerism and } \\
\text { idea diversity is } \\
\text { compromised. }\end{array}$ \\
\hline
\end{tabular}

GS technology overcomes these constraints by allowing students to choose any group boards that they wished to view and comment upon, by merely clicking on the drop down menu bar. Physical movement is minimised (Figure 7) and therefore, occurrences in misbehaviour are reduced without compromising students' volunteerism and epistemic agency. In this way, idea diversity and peer to peer learning remain unbounded as each group board has an equal probability of being 
chosen to be viewed and commented upon by each student. In our research study, we notice that the GS groups tend to be quieter, more engaged individually, and more on task, as compared to the PS groups shown in Figure 6. In short, GS technology favours individual commenting, questioning and learning during swapping of group boards, because individual choice is better preserved, compared with PS.

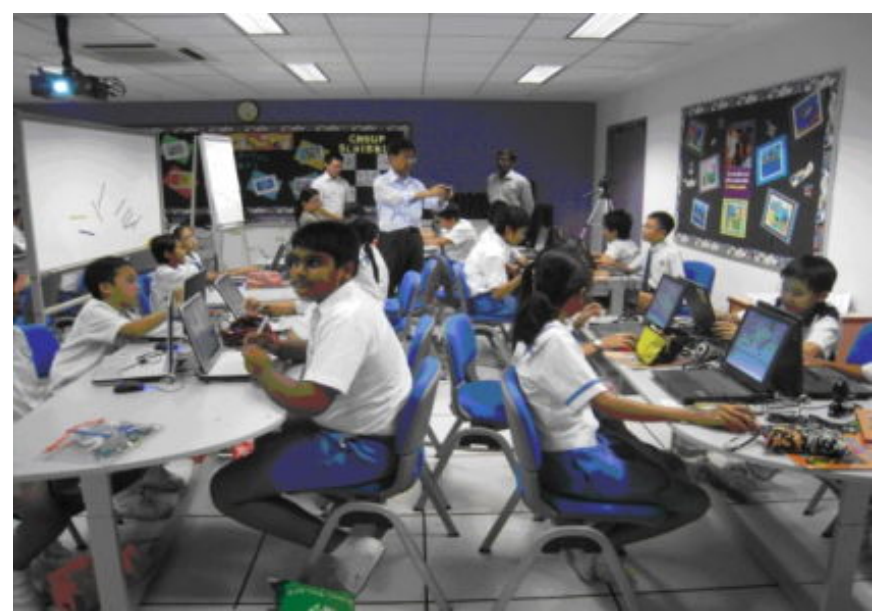

Figure 7: Minimal physical movement in the GS groups

Another observed phenomenon in PS is more verbal communications among the group members, as compared to GS technology. As mentioned above, we observe that the PS groups always exhibit higher noise levels, as compared to the GS groups during any group activity. Our anecdotal evidences (shown in Figure 8) indicate the presence of tablet PCs in GS lessons has posed a physical barrier in face to face verbal communication. In contrast, there are no physical barriers in communicating verbally in PS.

Another reason could be the different natures of the group boards inherent in both technologies. In GS technology, every group member has access to their own individual virtual group boards, displayed on the tablet PCs as compared to one common physical group board that is visually and physically accessible to all group members in PS technology as shown in Figure 9.

Hence, the physical referencing to the shared common group artefact, termed as "group referent artefact" by all group members, has encouraged more face to face talk. For example, in our study, we observed the following excerpt in a GS group:

Student A: Hey, what do you think of this comment on the yellow scribbles pad?

Student B: Which yellow scribble pad?

Student A: The one that is next to the black scribble pad.

(There was a time of silence as student B figures which pad that student

A is talking about)

Student B: I cannot find (slightly frustrated)

(Student A then turns the tablet PC around to face student B)

Student A: This is the scribble pad I was talking about!

(Using a finger to point to the yellow scribble pad) 


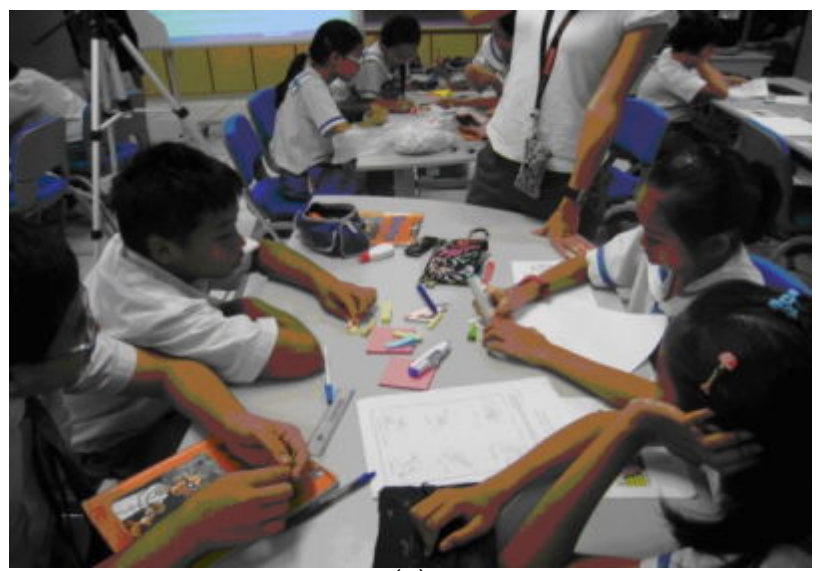

(a)

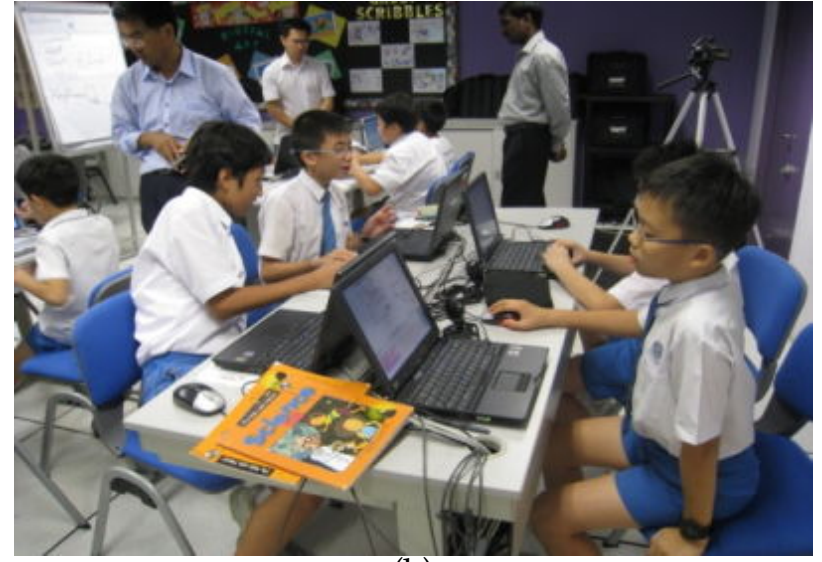

(b)

Figure 8: (a) No physical barrier in face to face communication in PS groups (b) Tablet PCs posed a physical barrier in face to face communication in GS groups.

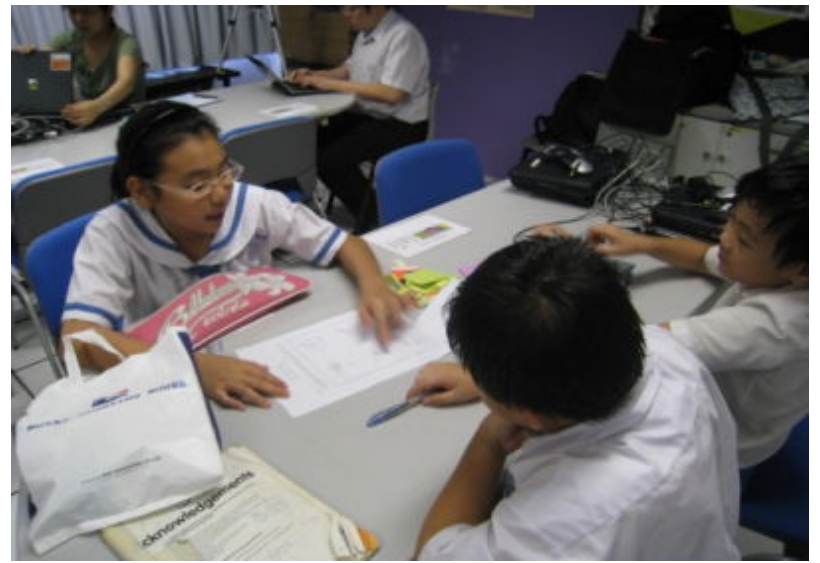

Figure 9: Group referent artefact in PS 
Evidently, it is more difficult for a student to describe the physical location of a particular GS scribble pad verbally to another student. This is especially so if language is a problem. GS technology does not allow a student to point physically to a referent material as conveniently as a PS technology. In addition, GS technology enables easier copying and replications of virtual posts as compared to PS physical posts. Through the "clone" and "backspace" features in GS technology, students are given opportunities to correct any mistakes, modify and replicate any ideas conveniently without the hassle of changing Post-It slips or untidy cancellation of any mistakes in the written ideas in PS technology. These latent features in these technologies have encouraged students to discuss and express their ideas in different sequences. Thus, students tended to articulate their preliminaries thoughts through typing or writing on GS scribble pads.

In contrast, students only wrote their "final product" on the Post-It slips in PS to save the hassle of correcting mistakes, changing Post-It slips and using too many slips. Intermediate ideas are processed in the minds of the individual students or verbal discussions among the group members. Coupled with the "group referent artefact" as mentioned above, one can deduce verbal face to face communication is highly preferred in PS technology. This is coherent with what we observed in our study. In a free random student movement Gallery Walk shown in Figure 10, students in PS groups tended to congregate and move in their groups though each student was free to choose which group board to go to.

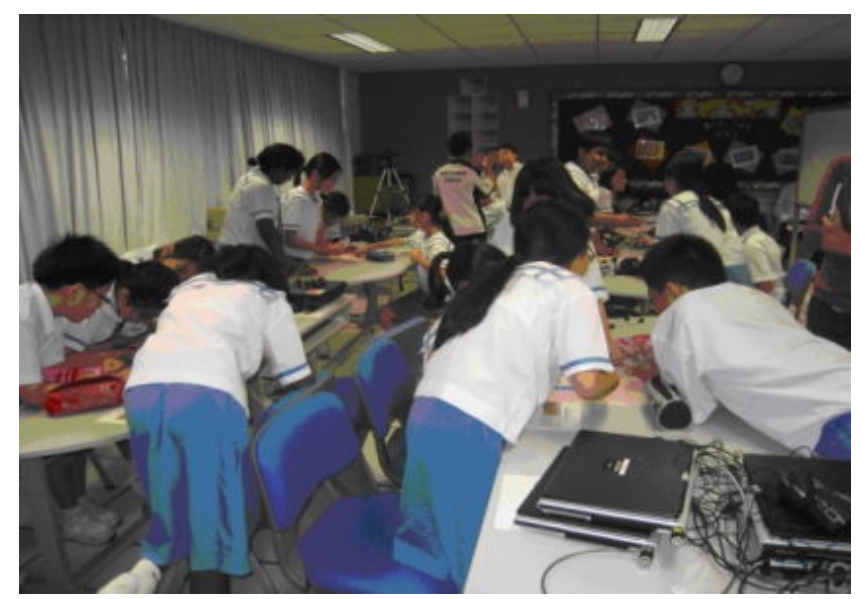

Figure 10: Group movements in the PS groups

The preference for face to face talk in PS ensures that students have their preferred talking partners around them (usually their own group members) when they move around. Hence, we observe a predominant "group movements" pattern instead of random individual students' movements in a PS enabled group activity. This also partially explains the noisier environment in a PS group activity. Therefore, PS and GS enable different group collaboration mechanisms. In PS, students brainstorm and verbally discuss their individual ideas together before putting down their final group ideas in writing. However, in GS, students apportioned some their individual thoughts in writing and some in verbal talk. Verbal talk is an articulation mode employed when ideas could not be adequately expressed in writing or typing. In addition, GS provides more ways (both writing and typing) to express their thought in words which then 
encourage students to employ language symbols or pictures as their primary mode of communication. In Figure 11, a schematic diagram illustrates the different mechanisms.
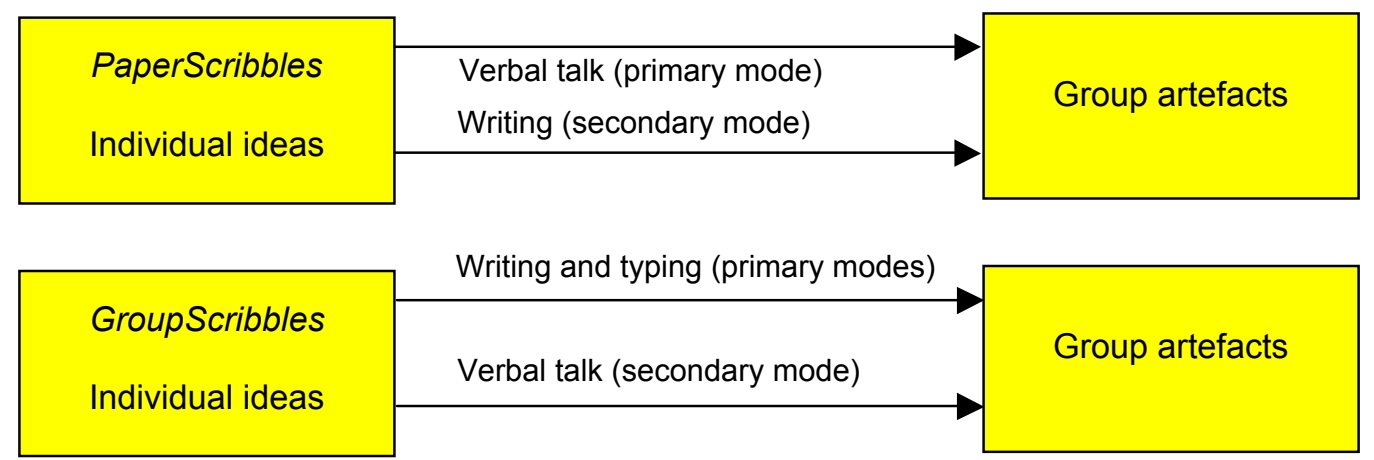

Figure 11: Different group collaboration mechanisms in PS and GS technologies

What then are the implications? The written and typed manifestations of students' thought processes in their GS private and group boards would assess individual students' thought processes better as compared to PS technology. In this way, GS technology possesses the potential to assess an individual's contribution in a group work. In our work, we are developing analytical tools that will help us identify and analyse individual students' postings. Moreover, anecdotal evidence indicated that the quality of individual students' ideas is higher in GS as they need to articulate their ideas in a clear fashion in writing or typing. This helps produce better group artefacts, especially in problem based learning. In our future work, different individual postings and group artefacts produced by PS and GS technologies will be analysed to ascertain the qualitative and quantitative differences.

Lastly, GS technology enables anonymity as compared to PS technology. This is helpful in encouraging shy students to contribute more ideas, reducing pressure to post ideas, and enables flexibility in signing off if recognition is desired. Below shows an excerpt from an interview with a student:

\footnotetext{
Interviewer: What do you think are the advantages of GS?

Student X: GS provides anonymity. I do not feel pressure to post as no one knows who has posted. Also, shy students like Student Y would not be afraid to post.

Interviewer: Okay. But if you want some recognition of your contribution, what would you do?

Student X: I would just sign my name on my posts if I want my friends and teachers to know that it is my post.
}

The multimodal feature (Chen \& Looi, 2008) of GS encourages students with different learning styles to express their ideas in different ways, producing a rich variety of ideas. PS technology allows much less anonymity. Apart from the fact that the act of writing and pasting one's ideas on the group board is highly visible to the surrounding students, the handwriting of each student may also reveal one's identity to another student.This discourages shy students from posting, especially if they are not confident about their ideas. Below is another excerpt from another interview with another student: 
Interviewer: Why are you still afraid to post though it is anonymous?

Student Z: Oh, my friends can recognise my handwritings!

Interviewer: (laughs).

Student Z: Yeah! It is true. I can recognise Student $\mathrm{Q}$ and $\mathrm{P}$ handwritings, you

know.

\section{Comparing PS and GS technologies}

From the preceding sections, we see that the different properties and characteristics of each PS and GS technology manifest different classroom phenomena. Table 2 provides a consolidated list (albeit not exhaustive) of the various dominant behaviours that were observed during the use of each technology.

Table 2: Comparison between PS and GS technologies

\begin{tabular}{|l|l|l|}
\hline \multicolumn{1}{|c|}{ Aspects } & \multicolumn{1}{|c|}{ PS technology } & \multicolumn{1}{c|}{ GS technology } \\
\hline Group collaboration & $\begin{array}{l}\text { Verbal talk as the primary mode } \\
\text { of communication }\end{array}$ & $\begin{array}{l}\text { Writing, typing and drawing as } \\
\text { primary modes of communication }\end{array}$ \\
\hline $\begin{array}{l}\text { Individual processing of } \\
\text { ideas }\end{array}$ & $\begin{array}{l}\text { Individual mental processing of } \\
\text { ideas }\end{array}$ & $\begin{array}{l}\text { Articulation of individual ideas } \\
\text { via writing, typing and drawing }\end{array}$ \\
\hline Ideas expressions & Write and draw & Typing, writing and drawing \\
\hline $\begin{array}{l}\text { Assessment of individual } \\
\text { contribution in group }\end{array}$ & -------------- & $\begin{array}{l}\text { Potential to assess articulated idea } \\
\text { contributions from each student }\end{array}$ \\
\hline Anonymity & Non anonymity & Anonymity \\
\hline
\end{tabular}

From Table 2, we can infer that PS and GS result in different uses and outcomes. This is not a question of which technology is "better"; it depends on the lesson objectives, assessment criteria and the class profile. The lesson objectives and the class profile will determine the suitability of each technology. For example, in a Tamil language class placing emphasis on writing and speaking, PS may be a better technology to use to achieve lesson objectives. For example, learning new vocabulary without the assistance of a language tool in the computer, points to the PS technology as a better technology to leverage upon. In a class where students are predominantly shy and afraid to speak up, GS technology may provide a better platform for students to express their ideas. If a teacher wants to assess student's collaboration in group work, GS may provide a better capability to capture this data. Future research work will be carried out to analyse and compare in more detail students' learning outcomes from employing the two technologies.

\section{Conclusion}

In this paper, we have discussed the salient differences between PS and GS technologies. The different behaviours with each technology are a result of the inherent physical and technological properties of each. One cannot assume that the pedagogical outcomes for both technologies are similar. The suitability of each technology depends on the lesson objectives, assessment criteria and class profile. In order to leverage technology fully, the teacher should gauge the alignment of the properties of each technology with the lesson objectives, assessment criteria and class profile in order that learning can be maximised for each student. As Mehan (1989) states, "it is what people do with machines, not the machine itself that makes a difference." 


\section{Acknowledgments}

This material is based on the work supported by the National Science Foundation (United States) under Grants 0427783 and 0713711 and by the National Research Foundation (Singapore) under Grant NRF2007-IDM003-MOE-001. Any opinions, findings, and conclusions or recommendations expressed in this material are those of the authors and do not necessarily reflect the views of the National Science Foundation or the National Research Foundation. The GS software has been made available as a free download by SRI International and the National Institute of Education (Singapore) and source code is available to project collaborators who sign a licensing agreement for research purposes. We are also grateful to Mayflower Primary School for collaborating with us on this research.

\section{References}

Cazden, C. (1988). Classroom discourse: The language of teaching and learning. Heinemann, Portmouth.

Chen, W. \& Looi, C. K. (2010). Active classroom participation in a Group Scribbles primary science classroom. British Journal of Educational Technology. http:/ / dx.doi.org/10.1111/j.14678535.2010.01082.x

Chen, F. H., Looi C. K. \& Chen, W. (2009). Integrating technology in the classroom: A visual conceptualization of teachers' knowledge, goals and beliefs. Journal of Computer Assisted Learning, 25(5), 470-488.

Chen, W. L. \& C. K. Looi (2008). Enhancing learning by rapid collaborative knowledge building in two science classrooms. Proceedings of the International Conference on Computers in Education, Taipei. [verified 1 Jul 2010]

http:/ / gs.lsl.nie.edu.sg/publication/ICCE\%20CHEN\%20LOOI\%20ICCE\%202008.pdf

Chen, F. H. \& C. K. Looi (2008). Integrating technology in the classroom: A study of a teacher's goals, knowledge and beliefs. Proceedings of the 2 nd Asia Pacific Educational Research Conference (APERA 2008), Singapore.

Chen, F. H. \& W. L. Chen (2009). School-based research in Group Scribbles: Sustaining and creating impact in schools. In Proceedings of the 3rd Redesigning Pedagogy International Conference, NIE, Singapore.

DiGiano, C., Tatar, D. \& Kireyev, K. (2006). Learning from the Post-It: Building collective intelligence through lightweight, flexible technology. In Conference on Computer Supported Cooperative Work, Banff. [verified 24 Jun 2010] http:/ / groupscribbles.sri.com/download/papers/DiGianoCSCW2006.pdf

Edwards, A. D. \& Westgate, D. P. G (1994). Investigating classroom talk. Falmer Press, London.

Gibson, J. J. (1977). The theory of properties. In R. Shaw \& J. Bransford (Eds), Perceiving, acting and knowing: Toward an ecological psychology (pp.67-82). Hillsdale, NJ: Erlbaum

Group Scribbles (2010). SRI International. http: / /groupscribbles.sri.com/

Guribye, F., Andreassen, E. F. \& Wasson, B. (2003). The organization of interaction in distributed collaborative learning. In B. Wasson, S. Ludvigsen \& U. Hoppe (Eds.), Designing for change in networked learning environments (pp. 385-394). Boston: Kluwer. 
Hake, R. R. (1998). Interactive-engagement vs. traditional methods: A six-thousand student survey of mechanics test data for introductory physics courses. American Journal of Physics, 66, 64-74. [report version verified 1 Jun 2010] http: / / www.eric.ed.gov:80 / ERICWebPortal/contentdelivery/servlet/ERICServlet?accno=E D441679

Looi, C. K., Chen, W. \& Ng, F.-K. (2010). Collaborative activities enabled by GroupScribbles (GS): An exploratory study of learning effectiveness. Computers $\mathcal{E}$ Education, 54(1), 14-26.

Looi, C. K., Chen, W. \& Patton, C. M. (2010). Principles and enactment of rapid collaborative knowledge building in classrooms. Educational Technology Magazine, September.

Looi, C. K., Chen, W. L., Tan, S., Wen, Y. \& Wee, J. D. (2008). Towards analysis of group interaction processes mediated by a rapid collaborative learning environment. Proceedings of the International Conference on Computers in Education, Taipei. [verified 1 Jun 2010] http: / / gs.lsl.nie.edu.sg/ publication/ICCE\%20LOOI\%20CHEN\%20ICCE\%202008.pdf

Mehan, H. (1989). Microcomputers in classrooms: Educational technology or social practice? Anthropology E Education Quarterly, 20(1), 4-22.

Mercer, N. (1995). The guided construction of knowledge: Talk amongst teachers and learners. Multilingual Matters Ltd, Clevedon.

Nassaji, N. \& Wells, G. (2000) What's the use of triadic dialogue? An investigation of teacherstudent interaction. Applied Linguistics, 21(3), 376-406.

Ng, F. K., Looi, C. K. \& Chen, W. (2008). Rapid collaborative knowledge building: Lessons learned from two primary science classrooms. Proceedings of the International Conference on the Learning Sciences, Utrecht. International Society of the Learning Sciences. http: / / gs.lsl.nie.edu.sg/ publication/Final\%20ICLS\%202008\%20(Ng\%20\&\%20Looi\%20\&\%20 Chen).pdf

Norman, D. A. (1990). The design of everyday things. New York: Doubleday.

Scardamalia, M. (2002). Collective cognitive responsibility for the advancement of knowledge. In B. Smith (Ed.), Liberal education in a knowledge society (pp. 67-98). Chicago: Open Court.

Tan, Y. L. N., Chen, W. \& Looi, C. K. (2009). GroupScribbles as a rapid CSCL tool: Learning experiences of pre-service teachers. In Proceedings of the 17th International Conference on Computers in Education 2009, Hong Kong: Asia-Pacific Society for Computers in Education. [verified 24 Jun 2010] http: / / www.apsce.net/ ICCE2009/ pdf/C2/ proceedings253-260.pdf

Chen Fang Hao, Lecturer, Learning Sciences and Technologies Group

National Institute of Education

Nanyang Technological University

1 Nanyang Walk, Singapore 637616 Email: fanghao.chen@nie.edu.sg

Web: http: / / eduweb.nie.edu.sg/LST/facultyandstaff/ChenFangHao.asp\# 